\title{
EXPERIENTIA DOCET
}

\section{Boris Aberšek}

University of Maribor, Slovenia

Theoretical insights, as well as basic and especially applied research, should never be self-serving, because it is only through their use that they can encourage the development of both, the individual, and the society as a whole. If this is true on a general level, it is all the more so in the sphere of education, considering that a country's education system is the basis for its progress and the groundwork for its future. Changes in education, however, occur very slowly, since education systems are some of the largest and most complex systems in every society and are impossible to change overnight. Today, the current opinion and understanding is that the knowledge that formed the basis of progress in the 19th and 20th centuries is definitely insufficient in the modern world (the $21 \mathrm{st}$ century). It will be even less so in the future, when the fourth industrial revolution will be reached. Collaboration between various scientific disciplines is welcome, but it is no longer enough. The quality and added value of an individual's competences, skills, and knowledge represent a basis for developing competitive advantages in the global world, and, in turn, increase the well-being of the entire society (Flogie et al., 2019).

A common feature of successful education systems is the balance between tradition and the capacity to be flexible and able to adapt to current social trends, i.e., the balance between research, development, and the application of discoveries made by research and development in general practice. We will have to make a step forward in the field of knowledge, skills and competences of a modern society of the future. The quality and added value of an individual's competences, skills, and knowledge represent a basis for developing competitive advantages in the global world. Classroom-oriented education does not allow reaching expected results needed for employment in the 21st century. The primal basis or the nature of scientific reasoning, on which many modern scientific and philosophical models are based, for example, deduction and induction, reasoning according to the best explanation - Hempel's scientific explanation's covering-law model, are still in use today. Also, certain fields, which have been occurring for a good part of our history (for example, the traditional feud between scientific realism and antirealism or instrumentalism), continue to be a part of modern philosophical debates even today. Philosophy of science, philosophy of technology and other philosophical approaches set the foundations of the development of modern society. It is more than obvious that in the field of development of modern concepts (both technological and educational), principles and concepts from different scientific disciplines need to be interconnected into a unified whole (Okasha, 2002). Both in theory and in practice, these developments should be considered on a systemic level, while taking into account the dynamic systems theory. The way to innovative modern education in the 21 st century is definitely paved by the field of cognitive science (Aberšek et al, 2017).

In the last decades, cognitive science has experienced rapid development. Especially because of the advancements in neuroscience, we are gradually beginning to realize that it is possible to scientifically research mental occurrences, and even consciousness - a field, which was until recently, reserved only for mystics. Cognitive scientists are trying to transfer their findings into practice - especially in the field of learning and teaching, 
processes of collaborative work, and in the field of machine learning and deciding. Study programs of cognitive science, which have blossomed in important universities worldwide over the last twenty years, are most often presented alongside some constitutive discipline (e.g., cognitive linguistics, cognitive neuroscience, cognitive anthropology, etc.). However, it is becoming increasingly clear that only an equal consideration of all fields can ensure a comprehensive discussion of mental and learning processes and consequently the processes involved in teaching (Aberšek et al, 2017).

While evidence of success and enthusiasm over innovative forms of teaching, learning and education are increasing, problems faced in the attempts to change practices in established institutions and organizations are becoming more and more apparent, and their resolution increasingly urgent. Nowhere else is the challenge of innovation more great, than in the field of education, where centuries-old teaching practices are etched into political and organizational structures, which are resistant to new ideas even in spite of the growing evidence which suggests that traditional ways of working do not pay off. In order to be able to face this challenge, and overcome the reluctance to change, the contributions in this journal defend the position that more attention needs to be paid to the implementation of research and development insights, than to development in itself. In schools, these shifts should be designed in such a way to enable the improvement of classroom practice, i.e., the practice of teaching and learning. The fruits of research are thus used to set up such school structures, which enable certain social practices, and limit others (Dumont et al., 2012).

Why is it so difficult to foster and keep alive a deep-seated culture of innovation in education (Aberšek, 2016)? There are several answers to this question. A frequently used argument is that education, in comparison to other service-providing organizations (especially those from the field of healthcare), works with a relatively weak knowledge base (Dumont et al., 2012). In spite of the fact that the research base about the practices that have proven to be effective in supporting learning and development, is modest, the majority of policy-makers, researchers and practitioners are not even aware of it, let alone supporting (or sometimes questioning) their own actions. What is even more concerning is that there are no established ways of including new knowledge in institutional practices in such a way to improve the professional practice and the results of learning (Aberšek, 2015).

For education providers who are part of the system, there is a relatively nondifferentiated range of roles available, there are few requested protocols for a systematic inclusion of good practices for class activity management, and, in addition, there is a lack of systematic induction of new members into the practice. The result is that education is still too conservative. Therefore, perhaps the best way of anticipating which practices are going to dominate in the majority of countries over the next five to ten years, is to describe the current situation in Slovenia, as part of the project Innovative Learning Environments, which is taking place between 2017 and 2022.

\section{References}

Aberšek, B. (2015). Changing educational theory and practice. Problems of Education in the 21st Century, 66, 4-6. https://dx.doi.org/10.33225/pec/15.66.04

Aberšek, B. (2016). Schola ludus. Journal of Baltic Science Education, 15(5), 556-558. http://www. scientiasocialis.lt/jbse/?q=node $/ 523$ 
Aberšek, B., Barle Lakota, A., Borstner, B., Bregant, J., Dolenc, K., Flogie, A., Gartner, S., Kordigel Aberšek, M., Rutar Leban, T., Šverc, A., Štraus, M., \& Ploj Virtič, M. (2017). Cognitive science in education and alternative teaching strategies. Cambridge Scholars Publishing.

Dumont, H., Istance, D., \& Benavides, F. (2012). The nature of learning. OECD.

Flogie, A., \& Aberšek, B. (2019). The impact of innovative ICT education and AI on the pedagogical paradigm. Cambridge Scholars Publishing,

Okasha, S. (2002). Philosophy of science. Oxford University Press.

Received 09 April 2021; Accepted 18 June 2021

Cite as: Aberšek, B. (2021). Experientia docet. Gamtamokslinis ugdymas / Natural Science Education, 18(1), 4-6. https://doi.org/10.48127/gu-nse/21.18.04

\section{Boris Aberšek}

$\mathrm{PhD}$, Professor, University of Maribor, Faculty of Natural Sciences and Mathematics, 2000 Maribor, Slovenia.

E-mail: boris.abersek@um.si

Website: https://scholar.google.com/citations?user=aRid0w4AAAAJ\&hl=en

ORCID: http://orcid.org/0000-0003-0563-7329 